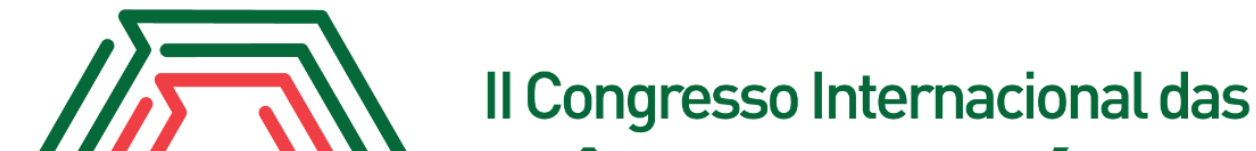 Ciências Agrárias COINTER - PDVAgro 2017
}

\section{EFEITOS DA APLICAÇÃO DE HERBICIDAS EM PRÉ-TRANSPLANTIO NO CRESCIMENTO INICIAL DE PLANTAS DE MELÃO AMARELO}

\begin{abstract}
Apresentação: Pôster
Jesley Nogueira Bandeira ${ }^{1}$; Claudia Dayanne Melo de Freitas ${ }^{2}$; Julianna de Paiva Pamplona ${ }^{3}$; Paulo Sérgio Fernandes das Chagas ${ }^{4}$; Daniel Valadão Silva ${ }^{5}$
\end{abstract}

\section{Introdução}

O cultivo do melão amarelo (Cucumis melo var. inodorus Naud.) no Brasil tem grande importância econômica por ser um dos frutos mais exportados pelo país (IBGE, 2015). A região Nordeste é a principal produtora de melão, contribuindo com mais de $90 \%$ da produção nacional. A expansão da cultura na região se deve à atuação de grandes empresas, que destinam boa parte da sua produção para exportação (SEBRAE, 2016).

Dentre os fatores que afetam o cultivo do meloeiro, a presença das plantas daninhas destacase como um dos mais importantes. Estas interferem negativamente na produtividade e na qualidade dos frutos colhidos, pois competem com a cultura por água, luz e nutrientes, hospedando pragas e doenças, além de dificultar a realização dos tratos culturais e colheita dos frutos. As plantas infestantes, quando não controladas, podem causar perdas de até $100 \%$ na produtividade de frutos comercializáveis de melão (TOMAZ, 2008).

A utilização de herbicidas constitui uma medida eficiente no controle das plantas daninhas. Entretanto, seu uso no melão ainda é muito limitado, considerando-se que atualmente existem apenas dois herbicidas registrados para a cultura (methyl bromide e carfentrazone-ethyl) (AGROFIT, 2017).

Em face da importância da cultura para o Nordeste brasileiro, das perdas de produção inerentes às plantas daninhas e em virtude da carência de informações, o objetivo deste trabalho foi avaliar o efeito de herbicidas com potencial de seletividade sobre crescimento inicial da cultura do melão amarelo.

\footnotetext{
${ }^{1}$ Agronomia, Universidade Federal Rural do Semi-árido, jesley_nb@hotmail.com

${ }^{2}$ Mestrado em Fitotecnia, Universidade Federal Rural do Semi-árido, claudiamelof@hotmail.com

${ }^{3}$ Mestrado em Fitotecnia, Universidade Federal Rural do Semi-árido, juliana_paiva_pamp@hotmail.com

${ }^{4}$ Mestrado em Ambiente, Tecnologia e Sociedade, Universidade Federal Rural do Semi-árido, paulosfc@ufersa.edu.br

${ }^{5}$ Professor Doutor, Universidade Federal Rural do Semi-árido, daniel.valadão@ufersa.edu.br
} 


\section{Fundamentação Teórica}

A concentração da produção de melão na região Nordeste se dá pelas condições edafoclimáticas favoráveis e localização geográfica privilegiada, a qual favorece exportação de seus produtos para Europa e América do Norte (FERNANDES, 2010). Embora possua muitas características favoráveis, existem muitos fatores que interferem negativamente a produtividade do meloeiro nessa região, com destaque para as plantas daninhas.

Segundo Silva et al. (2007), o controle dessas plantas daninhas nos campos de produção de melão vem sendo realizado pelo o uso do filme de polietileno (mulching). A eficiência desse método se dá pelo recobrimento do solo, suprimindo as plantas daninhas, e pela redução da perda de água por evaporação. Contudo foi verificada a ineficiência de controle das plantas daninhas no colo da planta, a elevação dos custos da produção relacionados à matéria prima e a de mão-de-obra durante sua instalação no campo.

O uso de herbicidas para o controle de plantas daninhas na cultura do meloeiro tem sido bastante cogitado pelos pesquisadores, em resposta a elevada eficácia no controle e na redução de custos de produção (OLIVEIRA et al., 2013). Entretanto, seu uso ainda é limitado devido a sensibilidade que a espécie possui a esse compostos químicos, existindo apenas dois herbicidas registrados para a cultura na plataforma AGROFIT (2017). As informações encontradas utilizadas pelos produtores referem-se a outras espécies Cucurbitáceas. Sonnenberg (1985) relata o uso dos herbicidas DCPA e trifluralin nas culturas da abóbora e do pepino. Rodrigues e Almeida (1995) descrevem que os herbicidas DCPA e napropamide são registrados em outros países para controle de espécies daninhas na cultura da melancia, sendo poucas referências encontradas no Brasil.

\section{Metodologia}

O experimento foi realizado em casa de vegetação, na Universidade Federal Rural do SemiÁrido (UFERSA), Mossoró-RN. O delineamento foi inteiramente casualizado, com cinco repetições. Foram aplicados 10 herbicidas em pré-transplantio das mudas: flumioxazin (70 g i.a. ha ${ }^{-}$ $\left.{ }^{1}\right)$, ametrina (250 g i.a. ha $\left.{ }^{-1}\right)$, sulfentrazone (250 g i.a. ha $\left.{ }^{-1}\right)$, diuron (1600 g i.a. ha $\left.{ }^{-1}\right)$, metribuzin (360 g i.a. ha ${ }^{-1}$ ), clomazone (250 g i.a. ha $\left.{ }^{-1}\right)$, S-metholochlor (1440 g i.a. ha $\left.{ }^{-1}\right)$, oxyfluorfen (480 g i.a. ha $\left.{ }^{-1}\right)$, oxadiazon (750 g i.a. ha $\left.{ }^{-1}\right)$ linuron (450 g i.a. ha $\left.{ }^{-1}\right)$, mais uma testemunha sem aplicação. A aplicação foi realizada com um pulverizador de pesquisa Herbicat ${ }^{\circledR}$, com duas pontas XR 11002 , espaçadas em $50 \mathrm{~cm}$. A pressão foi de 0,25 Mpa e o volume de calda de $1601 \mathrm{ha}^{-1}$. Aos 10 dias após a emergência as mudas de melão amarelo transplantadas para vasos com 2,0 dm de solo, 24 horas após a aplicação dos herbicidas. 
Aos 7, 14 e 28 dias após a aplicação foram realizadas avaliações visuais de fitointoxicação nas plantas de melão utilizando-se uma escala de notas variando de 0 (ausência de sintomas) a 100 (morte das plantas) (SBCPD, 1995). Aos 28 dias as plantas foram colhidas, e realizadas as avaliações do número de folhas (NF), altura de plantas (AP), utilizando um paquímetro digital e massa seca total (MST), onde as plantas foram levadas à estufa com circulação forçada de ar a 65 ${ }^{\circ} \mathrm{C}$. Os resultados foram submetidos à análise de variância pelo teste $\mathrm{F}$ e as médias comparadas pelo teste de Scott-Knott a 5\% de probabilidade. Para as análises estatísticas foi utilizado o software Sisvar 5.6.

\section{Resultados e Discussões}

Analisando a fitointoxidade aos sete dias após a aplicação dos herbicidas (DAA), primeira época de avaliação, notou-se que o linuron, flumioxazin, clomazone e oxyfluofen, causaram baixa fitointoxicação, na cultura com níveis de 4,0\%, 10,0\%, 18,0\% e 20,0\%, respectivamente. Entretanto, os sintomas do diuron, a ametrina e o oxadiazon foram mais severos, acarretando necrose de folhas seguida de morte das plantas (Tabela 1). Resultado semelhante foi encontrado por El-Nahhal e Hamdona (2015), quando estudando a fitotoxicidade do diuron no trigo, melão e molokhia, constataram que o herbicida resultou em maior nivel de fitotoxidade na cultura do melão.

Tabela 1: Fitointoxicação de plantas aos 7, 14 e 28 dias após a aplicação (DAA) dos herbicidas, número de folhas (NF), altura da planta (AP) e massa seca total (MST) de plantas de melão amarelo. Mossoró, RN, UFERSA, 2017. Fonte: própria.

\begin{tabular}{lcccccc}
\hline Tratamentos & 7 DAA & 14 DAA & 28 DAA & NF* & AP* & MST* $^{*}$ \\
\hline Linuron & $4.00 \mathrm{D} * *$ & $99.60 \mathrm{~A}$ & $100.00 \mathrm{~A}$ & $0.00 \mathrm{C}$ & $0.00 \mathrm{~B}$ & $0.00 \mathrm{C}$ \\
Metribuzin & $78.00 \mathrm{~B}$ & $100.00 \mathrm{~A}$ & $100.00 \mathrm{~A}$ & $0.00 \mathrm{C}$ & $0.00 \mathrm{~B}$ & $0.00 \mathrm{C}$ \\
S-metholochlor & $42.00 \mathrm{C}$ & $93.00 \mathrm{~A}$ & $100.00 \mathrm{~A}$ & $0.00 \mathrm{C}$ & $0.00 \mathrm{~B}$ & $0.00 \mathrm{C}$ \\
Diuron & $100.00 \mathrm{~A}$ & $100.00 \mathrm{~A}$ & $100.00 \mathrm{~A}$ & $0.00 \mathrm{C}$ & $0.00 \mathrm{~B}$ & $0.00 \mathrm{C}$ \\
Ametrina & $95.00 \mathrm{~A}$ & $100.00 \mathrm{~A}$ & $100.00 \mathrm{~A}$ & $0.00 \mathrm{C}$ & $0.00 \mathrm{~B}$ & $0.00 \mathrm{C}$ \\
Oxadiazon & $100.00 \mathrm{~A}$ & $100.00 \mathrm{~A}$ & $100.00 \mathrm{~A}$ & $0.00 \mathrm{C}$ & $0.00 \mathrm{~B}$ & $0.00 \mathrm{C}$ \\
Flumioxazin & $10.00 \mathrm{D}$ & $95.60 \mathrm{~A}$ & $100.00 \mathrm{~A}$ & $0.00 \mathrm{C}$ & $0.00 \mathrm{~B}$ & $0.00 \mathrm{C}$ \\
Sulfentrazone & $50.00 \mathrm{C}$ & $59.00 \mathrm{~B}$ & $75.00 \mathrm{~B}$ & $6.20 \mathrm{~B}$ & $8.90 \mathrm{~A}$ & $0.52 \mathrm{~B}$ \\
Oxyfluorfen & $20.00 \mathrm{D}$ & $38.00 \mathrm{C}$ & $49.00 \mathrm{C}$ & $8.00 \mathrm{~A}$ & $10.10 \mathrm{~A}$ & $0.92 \mathrm{~B}$ \\
Clomazone & $18.00 \mathrm{D}$ & $12.00 \mathrm{D}$ & $17.00 \mathrm{D}$ & $6.40 \mathrm{~B}$ & $11.50 \mathrm{~A}$ & $0.63 \mathrm{~B}$ \\
Testemunha & 0.00 & 0.00 & 0.00 & $8.40 \mathrm{~A}$ & $9.80 \mathrm{~A}$ & $2.21 \mathrm{~A}$ \\
\hline C.V.(\%) & 28.12 & 14.85 & 12.55 & 18.84 & 20.38 & 9.74 \\
\hline
\end{tabular}

* Médias transformadas por $\sqrt{x+1}$; ** Médias seguidas de mesma letra nas colunas não diferiram estatisticamente pelo teste Schott-knott a 5\% de significância. 
Aos 14 DAA, observou-se que o clomazone foi o herbicida que apresentou menor fitotoxicidade, seguido pelo oxyfluorfen e sulfentrazone, com percentagens de 12,0\%, 38,0\% e $59,0 \%$, respectivamente. O S-metholochlor, o flumioxazin e o linuron foram responsáveis por elevados nível de injúria $(93,0 \%, 95,6 \%$ e 99,6\%). Lagoke et al. (1983) observaram que o herbicida linuron, controlou efetivamente as plantas daninhas, mas o melão não foi tolerante. Já os produtos metribuzin, diuron, ametrina e oxadiazon ocasionaram níveis de injúria de 100\% (Tabela 1). Efeito semelhante foi encontrado por Cantamutto et al. (1996) ao avaliar a aplicação pré-transplantio de herbicidas no cultivo de melão, constatando que o metribuzin não é recomendado para essa cultura devido ao seu efeito fitotóxico severo.

Na terceira avaliação (28 DAA), verificou-se que o clomazone, oxyfluorfen e sulfentrazone mantiveram os menores valores de fitointoxidade $(17,00 \%, 49,00 \%$ e 75,00\%). Apesar de esses produtos terem apresentado potencial seletivo para o melão amarelo, os níveis altos de intoxicação encontrados para o oxyfluorfen e sulfentrazone indica que a dose seja reduzida para uso dos produtos na cultura. Resultado semelhante foi encontrado por Bellinder et al. (1993), quando avaliando a eficiência do oxyfluorfen para controlar ervas daninhas em cucurbitáceas verificaram que o melão apresentou tolerância ao oxyfluorfen em todas as doses testadas.

Com relação a variável NF, verificou-se que os tratamentos contendo oxyfluorfen, clomazone, e sulfentrazone apresentaram NF inferiores a testemunha, possivelmente devido à queda de folha ocasionada pela atuação desses herbicidas nas plantas (Tabela 1). Já a AP não foi afetada pelo efeito dos herbicidas sulfentrazone, oxyfluorfen e clomazone, sendo estatisticamente iguais a testemunha. Para variável MST os tratamentos sulfentrazone, oxyfluorfen e clomazone ocasionaram elevada redução de massa seca em relação à testemunha, reflexo da intoxicação provocada pelos herbicidas.

\section{Conclusões}

Os herbicidas aplicados em pré-transplantio na cultura do melão amarelo influenciaram o crescimento inicial das plantas, afetando as variáveis NF, AP e MST. Os tratamentos com linuron, metribuzin, S-metholochlor, diuron, ametrina, oxadiazon e flumioxazin causaram níveis severos de fitointoxicação, resultando na morte das plantas. Os herbicidas sulfentrazone, oxyfluorfen e clomazone apresentaram menor interferência no crescimento inicial das plantas de melão amarelo, tendo potencial seletivo para a cultura, havendo necessidade de adequação das doses aplicadas. 


\section{Referências}

AGROFIT. Consulta de ingrediente ativo. Disponível em: <http://agrofit.agricultura.gov.br/agrofit_cons/principal_agrofit_cons>. Acesso em: 26/09/2017.

BELLINDER, R. R; BINNING, L. K; YOURSTONE, K. S; BONANNO, A. R; GORSKI, S. F; MAJEK, B. A; NEARY, P. E; BARON, J. J; HOLMDAL, J; WALLAC, R. W. Oxyfluorfen Under Clear Polyethylene Film Controlled Weeds in Transplanted Cucurbits. Weed Technology, v. 7, n. 3 , p. $585-593,1993$.

CANTAMUTTO, M. A; AYASTUY, M. E; ELISEI, V.R. Evaluacion de herbicidas de aplicacion temprana en el cultivo de melon detrasplante. Planta Daninha, v. 14, n. 1, 1996.

EL-NAHHAL, Y; HAMDONA, N. Phytotoxicity of Alachlor, Bromacil and Diuron as single or mixed herbicides applied to wheat, melon, and molokhia. SpringerPlus. v. 367, n.4, 2015.

FERNANDES, D. Interferência de plantas daninhas na produção e qualidade de frutos de melão nos sistemas de plantio direto e convencional. 2010. 53 p. Dissertação (Mestrado em Fitotecnia) Universidade Federal Rural do Semi-Árido, Mossoró, 2010.

IBGE - Instituto Brasileiro de Geografia e Estatística. Produção agrícola municipal: quantidade produzida, valor da produção, área plantada e área colhida da lavoura temporária. Disponível em: <http//www.ibge.com.br/sidra>. Acesso em: 22/09/2017.

LAGOKE, S. T. O; CHANDRA-SINGH, D. J; OLOGUNDE, O. O. Pre-emergence chemical weed control in 'Egusi' melon (Citrullus lanatus Thunb. Mansf) in the southern Guinea savanna of Nigeria. Crop Protection, v. 2, n. 2, p. 235-242, 1983.

OLIVEIRA, M.B.; ALVES, P.F.S.; TEIXEIRA, M.F. F.; SILVA, H.D.; SÁ, R.R.; CAMPOS, R.G.C.; et al.. Fitotoxicidade de herbicidas aplicados em diferentes épocas em pós-emergência do feijão-caupi. Revista Unimontes Científica, v.15, n.1, jan.2013.

RODRIGUES, B.N., ALMEIDA, F.S. Guia de Herbicidas. $3^{\text {a }}$ ed. Londrina: Benedito Noedi Rodrigues e Fernando Souza de Almeida, 1995. 675 p.

SEBRAE. O cultivo e o mercado do melão. Disponível em: <http://www.sebrae.com.br/sites/PortalSebrae/artigos/o-cultivo-e-o-mercado-domelao,5a8837b644134410VgnVCM2000003c74010aRCRD>. Acesso em: 26/09/2017.

SILVA, A. C. et al. Manejo integrado de plantas daninhas em hortaliças. In: FREITAS, F. C. L. et al. SIMPÓSIO SOBRE MANEJO DE PLANTAS DANINHAS NO SEMI-ÁRIDO, 1., 2007, Mossoró, 2007. Anais... Mossoró, 2007. p. 199-211.

SOCIEDADE BRASILEIRA DA CIÊNCIA DAS PLANTAS DANINHAS - SBCPD. Procedimentos para instalação, avaliação e análise de experimentos com herbicidas. Londrina: SBCPD, 1995. 42p.

SONNENBERG, P.E. Cultura das cucurbitáceas. In: Olericultura especial: $2^{\mathrm{a}}$ parte. $3^{\mathrm{a}}$ ed. Goiânia: Universidade Federal de Goiás, 1985. p. 108-49.

TOMAZ, H. V. Q. Manejo de plantas daninhas, crescimento e produtividade do meloeiro em sistemas de plantio direto e convencional. 2008. 67 p. Dissertação (Mestrado em Fitotecnia) Universidade Federal Rural do Semi-Árido, Mossoró, 2008. 